\title{
A NEW TYPE OF CURRENT CONVEYOR AND ITS APPLICATION IN FULLY BALANCED DIFFERENTIAL CURRENT-MODE ELLIPTIC FILTER DESIGN
}

\author{
Qiujing Zhang - Chunhua Wang ${ }^{*}$ - Jingru Sun — Sichun Du
}

\begin{abstract}
This paper introduces a new type of CMOS-based current conveyor: current controlled fully balanced second generation current conveyor (CFBCCII) element which has a pair of differential Y terminals, a pair of differential X terminals and two pairs of $\mathrm{Z}$ terminals. The proposed circuit offers electronic tuning possibilities by means of a current adjustable intrinsic resistance at its $\mathrm{X}$ terminal. An elliptic filter realization is described as an example for its application in a current-mode fully balanced filter design, where the intrinsic resistors in CFBCCIIs are used for the electronic tuning of the characteristic filter frequency.

K e y w ords: current mode, differential, current conveyor, elliptic filter
\end{abstract}

\section{INTRODUCTION}

The interest in designing current-mode circuits mainly emanates from their speed advantages, higher bandwidth, wider dynamic range, and relatively simpler circuitry $[1-$ 8]. Current conveyor (CCII) element and its modifications can be used in single-ended [1-7] or differential filters [8]. Differential current mode filters play an important part in telecommunications due to their ability of suppressing even harmonics, as well as common-mode interference. In a previous work, Chiu et al proposed a differential difference current conveyor (DDCC) and a second-order filter which can realize low-pass and band-pass filtering function [9]. In 1997, Elwan et al proposed two CMOSbased differential voltage current conveyor (DVCC) circuits [10], and this element found wide applications [11]. A fully differential current conveyor (FDCCII) [12] presented by El-Adawy employs fully differential structure to suppress undesirable common mode signals, and it has two X terminals and four Y terminals. A new realization of FDCCII was proposed by Soliman [13], and the terminals $\mathrm{X}, \mathrm{Y}$ and $\mathrm{Z}$ of this circuit are all differential.

In modern VLSI applications, balanced-mode structures are increasingly used. In a balanced circuit, output common mode (CM) signal is kept constant, and it is entirely independent of the input signal. Therefore, performance of a fully balanced structure (such as dynamic range, noise suppression, and harmonic distortion) can be largely improved. A fully balanced current conveyor proposed in [14] provides a pair of differential Y terminals and a pair of differential $\mathrm{X}$ terminals. The circuit introduces two common-mode feedback CMFB circuits which keep the common mode signal constant, while increasing the dynamic range of differential mode signals. In 2004, Alzaher introduced a CMOS fully differential current conveyor [15] also including two CMFB circuits.
However, in all of these previously reported elements, there exists a relatively significant voltage tracking error from terminal $\mathrm{Y}$ to terminal $\mathrm{X}$. This is because of the parasitic resistor in terminal $\mathrm{X}$ which leads to transfer function error in their application circuits. Several CCII circuits with reduced resistance in terminal $\mathrm{X}$ have been proposed these years [16-18], the CCII circuits in [16] and [17] result small input resistances in terminal $\mathrm{X}$, the circuit in reference [18] employs four transconductance amplifiers, which makes circuit complicated. Although the above three circuits minimize the voltage tracking error in conventional CCII, these elements lack electronic programmability, which has become a key feature in recent applications.

In 1996, Fabre proposed a current controlled current conveyor (CCCII) [22] constructed by a bipolar translinear loop, by introducing the intrinsic resistor, this circuit can rectify the transfer error between X and Y terminals, at the same time, the intrinsic resistor in $\mathrm{X}$ terminal can be adjusted by the bias current. However, it has a crucial disadvantage of having only one high input voltage terminal, which is not convenient to process differential or floating signals.

Differential or balanced CCCII is more attractive in application, since they are more sophisticated in dealing with differential and floating signals. In 2005, a CMOS CCII was proposed in [20], this circuit has a pair of differential voltage inputs $\left(Y_{1}\right.$ and $\left.Y_{2}\right)$, one current input $(X)$, and two differential current outputs $\left(Z_{+}\right.$and $\left.Z_{-}\right)$, it can reduce the harmonic distortion in some extent and can be integrated conveniently in CMOS technology. However, this circuit is not fully differential realization since $\mathrm{X}$ terminal is not differential, moreover, the circuit does not employ CM feedback (CMFB) circuit which can ensure the output signals symmetric and

Key Laboratory of Advanced Communication Technology in Hunan Universities, College of Information Science and Engineering, Hunan University, Changsha, 410082, Hunan, People's Republic of China, wch1227164@sina.com 


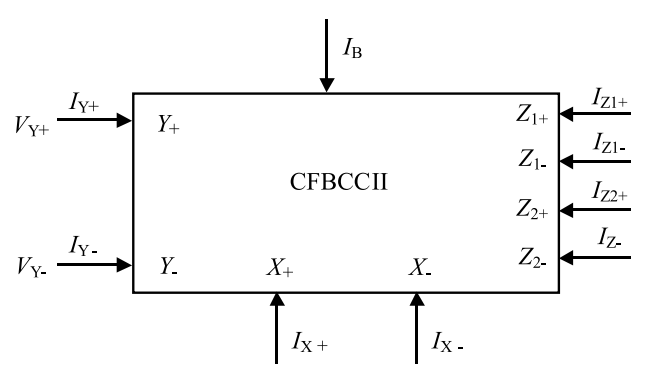

Fig. 1. Symbol of CFBCCII

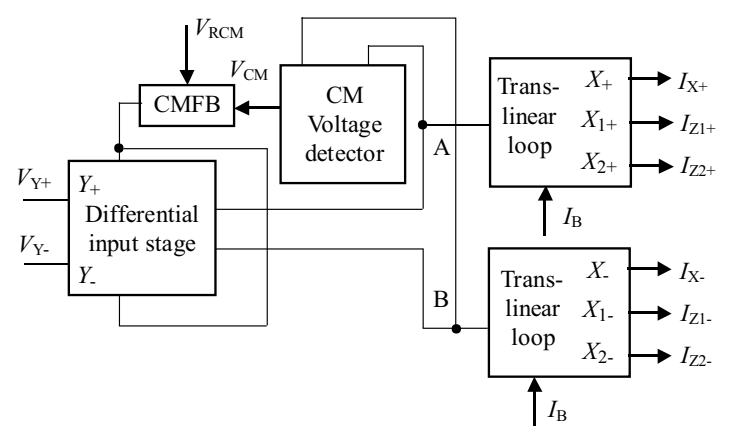

Fig. 2. Frame diagram of CFBCCII

make the CM signals independent of the input signal [15]. In 2006, a CMOS current controlled balanced integrator is presented in [21], this circuit is constructed by two CMOS translinear circuits and two floating capacitors, it has two differential voltage inputs and two differential outputs, but the current signal in X terminal can not be made differential, therefore, this circuit is not in fully balanced structure, moreover, the capacitors of the integrator are not grounded, and this would leads to large chip area when integrated in CMOS technology. The balanced tunable current conveyor presented in [19] has one voltage input, two differential current inputs, and two differential current outputs. The circuit introduced current tunability in terminals $\mathrm{X}$ and $\mathrm{Z}$ by changing the drain width of MOS transistors in the current mirrors, in this way, the current gain between terminal $\mathrm{X}$ and $\mathrm{Z}$ would be tuned. Obviously, the circuit is not fully balanced yet since terminal $\mathrm{Y}$ is single ended. Moreover, this circuit just realizes the controllability the current relationship between $\mathrm{X}$ and $\mathrm{Z}$, but does not realize the controllability of the voltage relationship between $\mathrm{Y}$ and $\mathrm{X}$, the voltage transfer error still exist. So its applications are limited.

On the other hand, the advantages of elliptic filters are well known, no other filters of equal order can have a faster transition in gain between the passband and the stopband, for the given values of the ripple, therefore, the selective character of elliptic filter is very attractive [23-28]. Various OTA based [23-25] elliptic filters were presented. However, the linearity and dynamic range of OTA based filters are not as good as CCII-based filters. On the other hand, the CCCII-based filters not only have better linearity, but also have easier electronic frequency adjusting characteristics. There are three different methods to implement analogue filters: cascade, multiple loop feedback (MLF), and LC ladder simulation. The LC ladder simulation has the lowest sensitivity and low component spread among the three methods.

This paper proposes a new element, so called a current controlled fully balanced second-generation current conveyor (CFBCCII) which employs a fully balanced structure to suppress common-mode signals. Compared with the circuit in [20], the proposed CFBCCII uses the fully balanced structure, and employs CMFB circuit to prevent the drift of CM signals. CFBCCII is also different from the circuit in [21], since all terminals of CFBCCII are differential, moreover, when connected as an integrator, the capacitors in the circuit can be grounded. By introducing a current adjustable intrinsic resistance at $\mathrm{X}$ terminal, CFBCCII eliminates the transfer error between $\mathrm{X}$ and $\mathrm{Y}$ terminals, moreover, it introduces the electronic tunability for itself and application circuits. So CFBCCII is different from the circuit in [22] in the manner of controllability, CFBCCII controls the voltage relationship between $\mathrm{X}$ and $\mathrm{Y}$ terminals, while the circuit in [22] controls the current relationship between $\mathrm{X}$ and $\mathrm{Z}$ terminals. Moreover, all terminals of CFBCCII are differential, while $\mathrm{Y}$ terminal is not differential in [22].

Based on the proposed element, this paper presents a fully differential current-mode elliptic filter realized by using signal flow graph approach to simulate a passive lowpass ladder network. The proposed filter employs $7 \mathrm{CF}$ BCCIIs, and it has the frequency tuning characteristic by adjusting the bias current of the active block.

\section{CFBCCII CIRCUIT AND ITS CMOS REALIZATION}

The circuit symbol of CFBCCII is shown in Fig. 1. Here, $Y_{+}, Y_{-}$are differential voltage input terminals exhibiting high input resistance. $X_{+}$and $X_{-}$behave as differential voltage tracking terminals, $Z_{1+}, Z_{2+}$ and $Z_{1-}$, $Z_{2-}$ are the current output terminals, the differential current at terminal $\mathrm{Z}$ is a replica of the differential current at terminal X. The number of current output terminal Z can be extended if necessary. $I_{B}$ denotes bias current of CFBCCII. The port characteristic of CFBCCII is represented by (1), $R_{X}=f\left(I_{B}\right)$ denotes the controlled resistance which can be tuned by $I_{B}$.

$$
\begin{aligned}
& I_{Y+}=I_{Y-}=0 \\
& V_{X+}-V_{X-}=\left(V_{Y+}-V_{Y-}\right)+\left(I_{X+}-I_{X-}\right) R_{X}, \\
& I_{Z 1+}-I_{Z 1-}=I_{Z 2+}-I_{Z 2-}=I_{X+}-I_{X-} .
\end{aligned}
$$

The circuit frame diagram of CFBCCII is given in Fig. 2. The circuit is made up of four blocks: The differential voltage input stage, the translinear loop [20], common mode $(\mathrm{CM})$ voltage detector, and the common mode feedback circuit (CMFB). The basic principle of the circuit is analyzed as follows: There are two signal-feed 


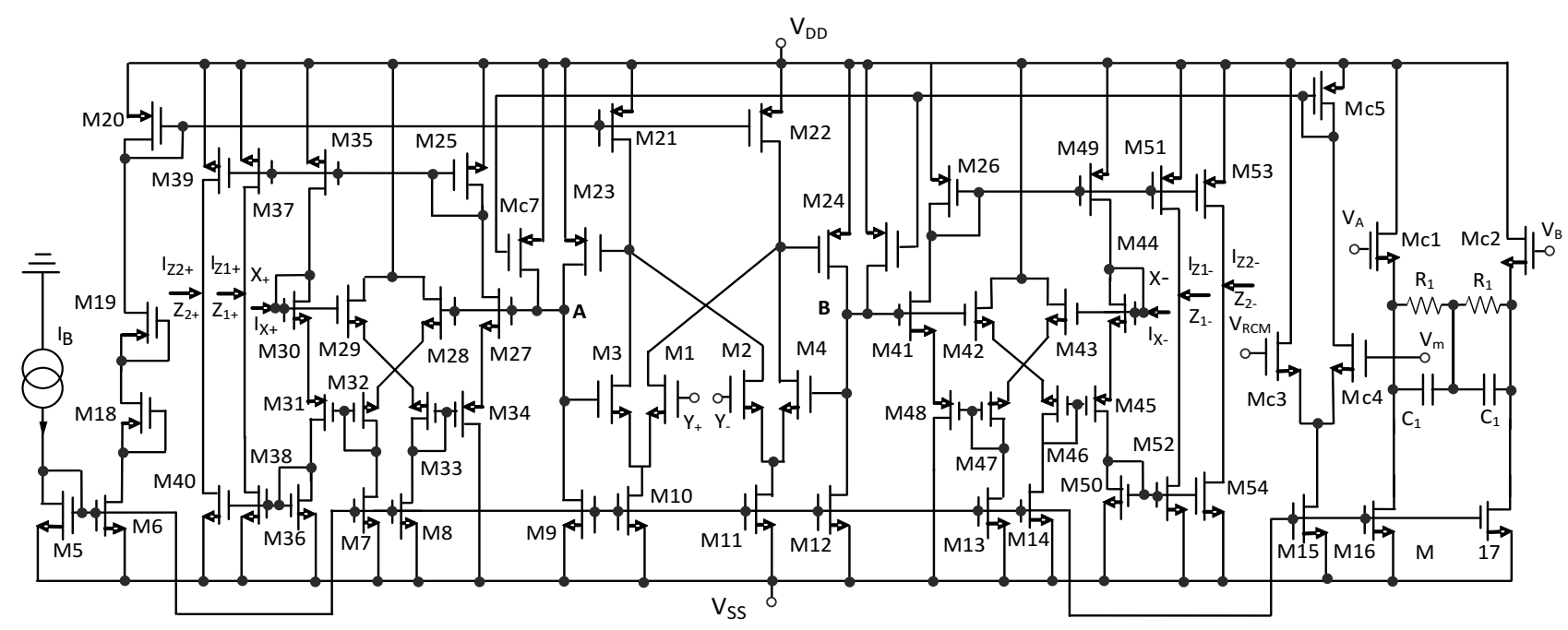

Fig. 3. Circuit realization of CFBCCII

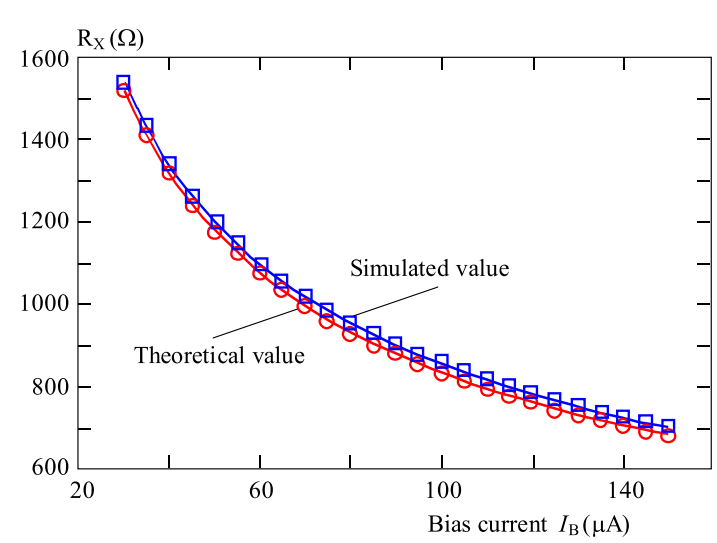

Fig. 4. Simulated relationship between $R_{X}$ and $I_{B}$

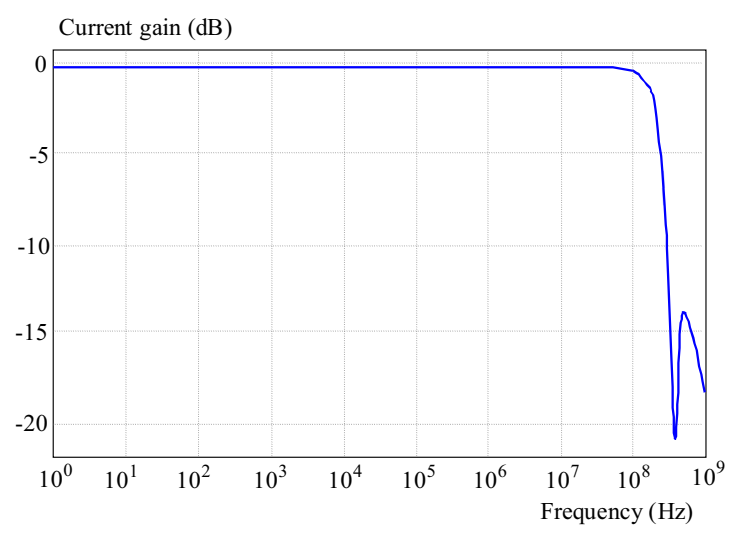

Fig. 5. Frequency response of $\mathrm{Z}-\mathrm{X}$ current gain

paths in the circuit, the feedforward path, and the feedback path. The feedforward path consists of a differential input stage and two translinear loops. Differential voltage signals are added to the differential input stage, and the voltages would be transferred to the points $\mathrm{A}$ and $\mathrm{B}$. The translinear loops are employed to transfer $V_{A}$ and $V_{B}$ to the output terminals. The feedback path consists of CM voltage detector and CMFB circuit. The voltages at the points $\mathrm{A}$ and $\mathrm{B}$ will be sampled by the $\mathrm{CM}$ voltage detector, where the common-mode $(\mathrm{CM})$ voltage $V_{\mathrm{CM}}$ is generated. The CMFB circuit is employed to suppress the CM signals, by comparing $V_{\mathrm{CM}}$ and $V_{\mathrm{RCM}}, V_{\mathrm{CM}}$ is forced to follow $V_{\mathrm{CM}}=V_{\mathrm{RCM}}$, in this way, the CM signal can be effectively suppressed. Here, $I_{B}$ is bias current of translinear loop.

The realization of the CFBCCII circuit is illustrated in Fig. 3. M1-M4 constitute two pairs of differential inputs, the parameters of the transistors are symmetric. $Y_{+}$ and $Y_{-}$are differential voltage input terminals. The two pairs of differential transistors are loaded by M10-M11 which carry equal bias currents $I_{B}$. M27-M34 and M41M48 constitute two CMOS translinear loops, M27-M34 transfer the voltage from point A to $X_{+}$, and M41-M48 transfer the voltage from point B to $X_{-}$. Now consider the translinear loop of M27-M34: M27 and M34, M28 and M32, M29 and M33, M30 and M31 constitute four compound transistors respectively. If the channel aspect ratios W/L of NMOS transistors in the four compound transistors are identical, and the ratios $\mathrm{W} / \mathrm{L}$ of PMOS transistors are alike (all transistors operate in saturation region), one can get [26]

$$
R_{X}=\left(2 \sqrt{2 K_{e f f}} \sqrt{I_{B}}\right)^{-1}
$$

where $K_{\text {eff }}=K_{n} K_{p} /\left(\sqrt{K_{n}}+\sqrt{K_{p}}\right)^{2}$ represents the compound transconductance coefficient of the compound transistors, $K_{n}$ and $K_{p}$ are the transconductance coefficient of the NMOS and PMS transistors respectively. $R_{X}$ represents the parasitic resistance of terminal $\mathrm{X}$, which is inversely proportional to the square root of bias current $I_{B}$. Namely $R_{X}$ can be adjusted by bias current $I_{B}$.

To verify the proposed circuit performance, CFBCCII shown in Fig. 3 is simulated using HSpice program. $0.35 \mu \mathrm{m}$ CMOS technology parameters are used. The dimensions of MOS transistors are listed in Table 1. Supply voltages used are $\pm 1.65 \mathrm{~V}$. Figure 4 shows the relationship between $R_{X}$ and bias current $I_{B}$, the comparison 


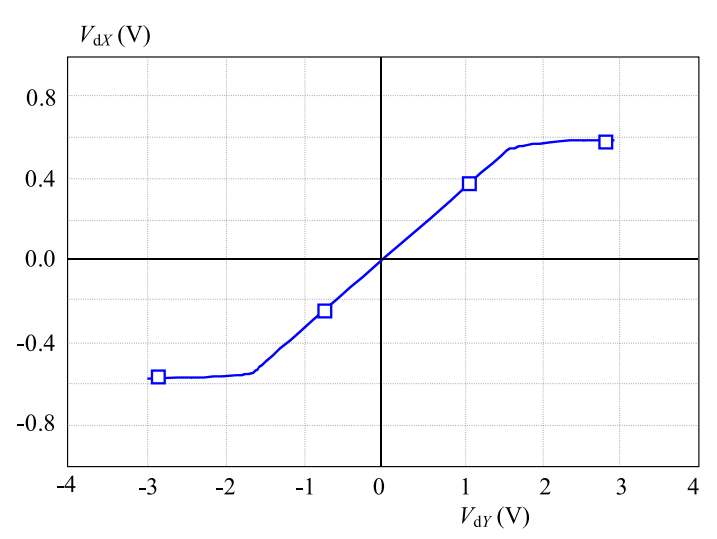

Fig. 6. Simulated Y-X DC characteristic

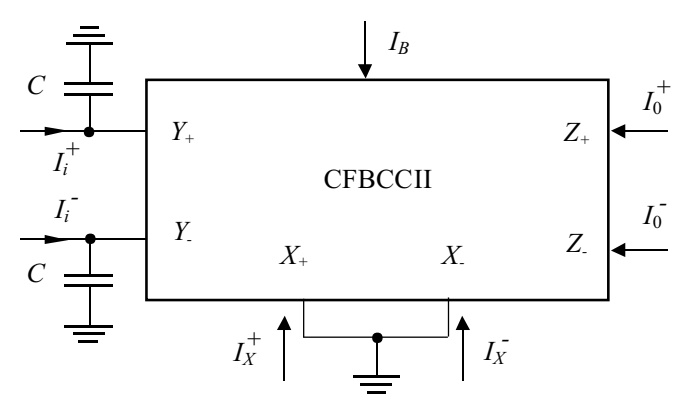

Fig. 8. CFBCCII based integrator

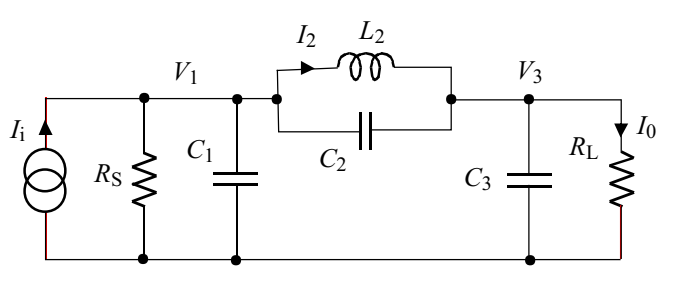

Fig. 10. The $3^{\text {rd }}$-order elliptic low-pass RLC ladder filter

Table 1. Dimensions (W/L) of MOS transistors in CFBCCII ( $\mu \mathrm{m})$

\begin{tabular}{|c|c|c|c|}
\hline $\begin{array}{l}\text { MOS } \\
\text { ransistors }\end{array}$ & $\begin{array}{l}\mathrm{W} / \mathrm{L} \\
(\mu \mathrm{m}) \\
\end{array}$ & $\begin{array}{c}\text { MOS } \\
\text { Transistors }\end{array}$ & $\begin{array}{l}\mathrm{W} / \mathrm{L} \\
(\mu \mathrm{m}) \\
\end{array}$ \\
\hline $\mathrm{M} 1 \sim \mathrm{M} 4$ & $2 / 0.35$ & M5-M14 & $16 / 0.35$ \\
\hline M15 & $80 / 0$ & $\begin{array}{l}\text { M16- } \\
\text { M18- }\end{array}$ & $10 / 0$ \\
\hline M20 & $14 / 0$. & M23, M24 & $20 / 0.35$ \\
\hline $\begin{array}{l}\text { M25-M } \\
\text { M40-N }\end{array}$ & $10 / 0$ & $\begin{array}{l}\text { M29- } \\
\text { M44- }\end{array}$ & $40 / 0$ \\
\hline $\begin{array}{l}\text { M33-M36 } \\
\text { M48-M51 }\end{array}$ & $80 / 0.35$ & $\begin{array}{l}\text { M37-M39 } \\
\text { M52-M54 }\end{array}$ & $4 / 0.3$ \\
\hline Mc1-Mc4 & $1 / 0.35$ & Mc5-Mc7 & $2 / 0.35$ \\
\hline
\end{tabular}

of the theoretical result and the simulated result are also given. Bias current varies from $30 \mu \mathrm{A}$ to $150 \mu \mathrm{A}$, while $R_{X}$ varies from $700 \Omega$ to $1540 \Omega$. Figure 5 shows the current transfer characteristics $\left(I_{Z+}-I_{Z-}\right) /\left(I_{X+}-I_{X-}\right)$ when nodes $Y_{+}$and $Y_{-}$are grounded, an excellent bandwidth with $-3 \mathrm{~dB}$ cutoff frequency of $200 \mathrm{MHz}$ can be obtained. is consistent with the differential input current

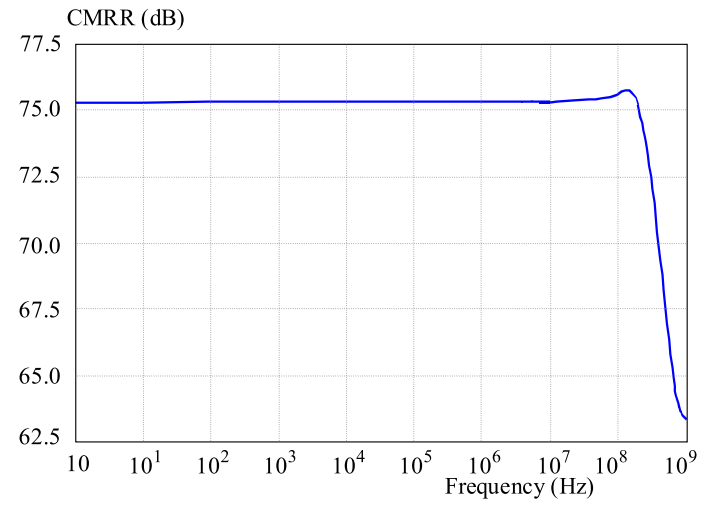

Fig. 7. Simulated CMRR of CFBCCII circuit

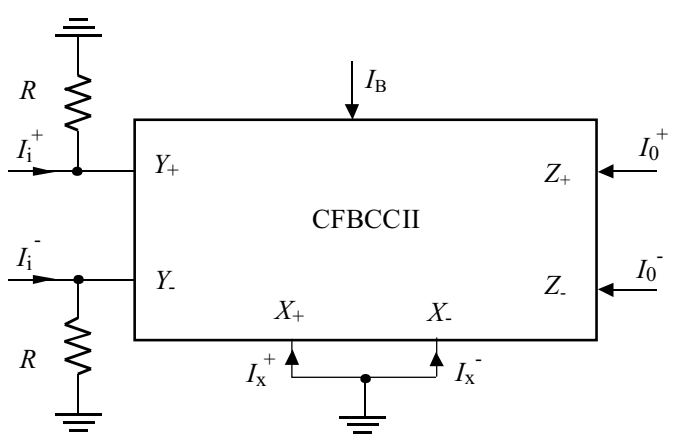

Fig. 9. CFBCCII based scaling circuit

$\left(I_{X+}-I_{X-}\right)$. Figure 6 shows the simulated DC transfer characteristic between $\mathrm{Y}$ terminals and $\mathrm{X}$ terminals, $V_{d Y}=V_{Y+}-V_{Y-}, V_{d X}=V_{X+}-V_{X-}$, the transfer characteristic between $\mathrm{Y}$ and $\mathrm{X}$ ports can be written as: $V_{d X}=V_{d Y}+\left(I_{X+}-I_{X-}\right) R_{X}$. Bias current is $50 \mu \mathrm{A}$. It is seen that the linearity input range is almost $3 \mathrm{~V}$. Simulated common mode reject ratio (CMRR) of this circuit is illuminated in Fig. 7, it shows that this circuit has a CMRR value of $75.2 \mathrm{~dB}$, and we can see that the circuit can reduce the undesirable common mode signals in a certain extent.

\section{CFBCCII BASED SUB-CIRCUIT FOR THE PROPOSED FILTER}

\subsection{Integrator}

Figure 8 shows the integrator based on CFBCCII. Routing analysis yields

$$
\begin{gathered}
I_{0}^{+}-I_{0}^{-}=I_{X}^{+}-I_{X}^{-} \\
\left(I_{i}^{+}-I_{i}^{-}\right) \frac{1}{s C}+\left(I_{X}^{+}-I_{X}^{-}\right) R_{X}=0 .
\end{gathered}
$$

The transfer function can be written as:

$$
H(s)=\frac{I_{0}^{+}-I_{0}^{-}}{I_{i}^{+}-I_{i}^{-}}=-\frac{1}{s R_{X} C} .
$$




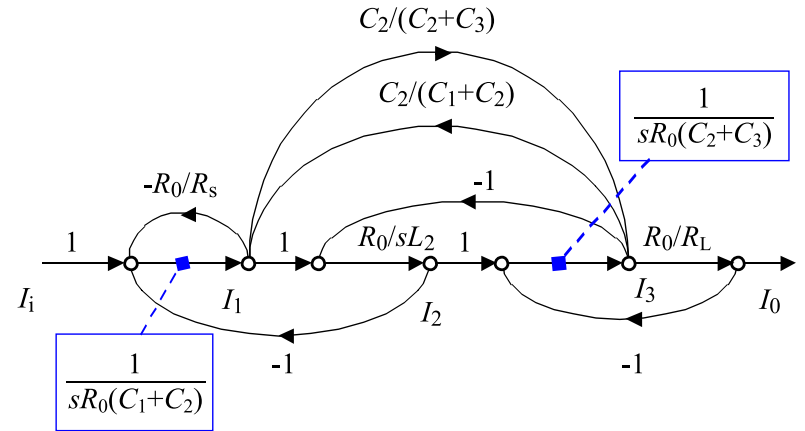

Fig. 11. Signal flow graph of the $3^{\text {rd }}$-order elliptic low-pass RLC ladder filter

\subsection{Scaling Circuit}

The CFBCCII based scaling circuit is shown in Fig. 9, whose transfer function is

$$
H(s)=\frac{I_{0}^{+}-I_{0}^{-}}{I_{i}^{+}-I_{i}^{-}}=-\frac{R}{R_{x}} .
$$

\section{THE PROPOSED FILTER}

\subsection{Design of The Filter}

Figure 10 shows the low-pass third-order passive LC ladder filter. The proposed elliptic filter can be designed by simulating the transfer functions in the SFG using the integrator and scaling circuits based on CFBCCII. From
Fig. 10, one can get the state equation represented as follows

$$
\begin{gathered}
V_{1}=\left[I_{1}-I_{2}-\left(V_{1}-V_{3}\right) s C_{2}-\frac{V_{1}}{R_{s}}\right] \frac{1}{s C_{1}}, \\
I_{2}=\left(V_{1}-V_{3}\right) \frac{1}{s L_{2}}, \\
V_{3}=\left[I_{2}+\left(V_{1}-V_{3}\right) s C_{2}-\frac{V_{3}}{R_{L}}\right] \frac{1}{s C_{3}}, \\
I_{0}=\frac{V_{3}}{R_{L}} .
\end{gathered}
$$

Converting the voltage signals into current signals by dividing a virtual resistor $R_{0}$, and $V_{1}=I_{1} R_{0}, V_{3}=$ $I_{3} R_{0}$, the state equations can be rewritten as

$$
\begin{gathered}
I_{1}=\frac{I_{i}-I_{1}\left(R_{0} / R_{S}\right)-I_{2}}{s R_{0}\left(C_{1}+C_{2}\right)}+\frac{I_{3} C_{2}}{C_{1}+C_{2}}, \\
I_{2}=\left(I_{1}-I_{3}\right) \frac{R_{0}}{s L_{2}}, \\
I_{3}=\frac{I_{2}-I_{3}\left(R_{0} / R_{L}\right)}{s R_{0}\left(C_{2}+C_{3}\right)}+\frac{I_{1} C_{2}}{C_{2}+C_{3}}, \\
I_{0}=I_{3} \frac{R_{0}}{R_{L}}
\end{gathered}
$$

According to the equations (9)-(12), the SFG can be obtained shown in Fig. 11. Substituting the scaler and integrator with CFBCCII based sub-circuits which have been analyzed in Section 3, the proposed filter is obtained as shown in Fig. 12.

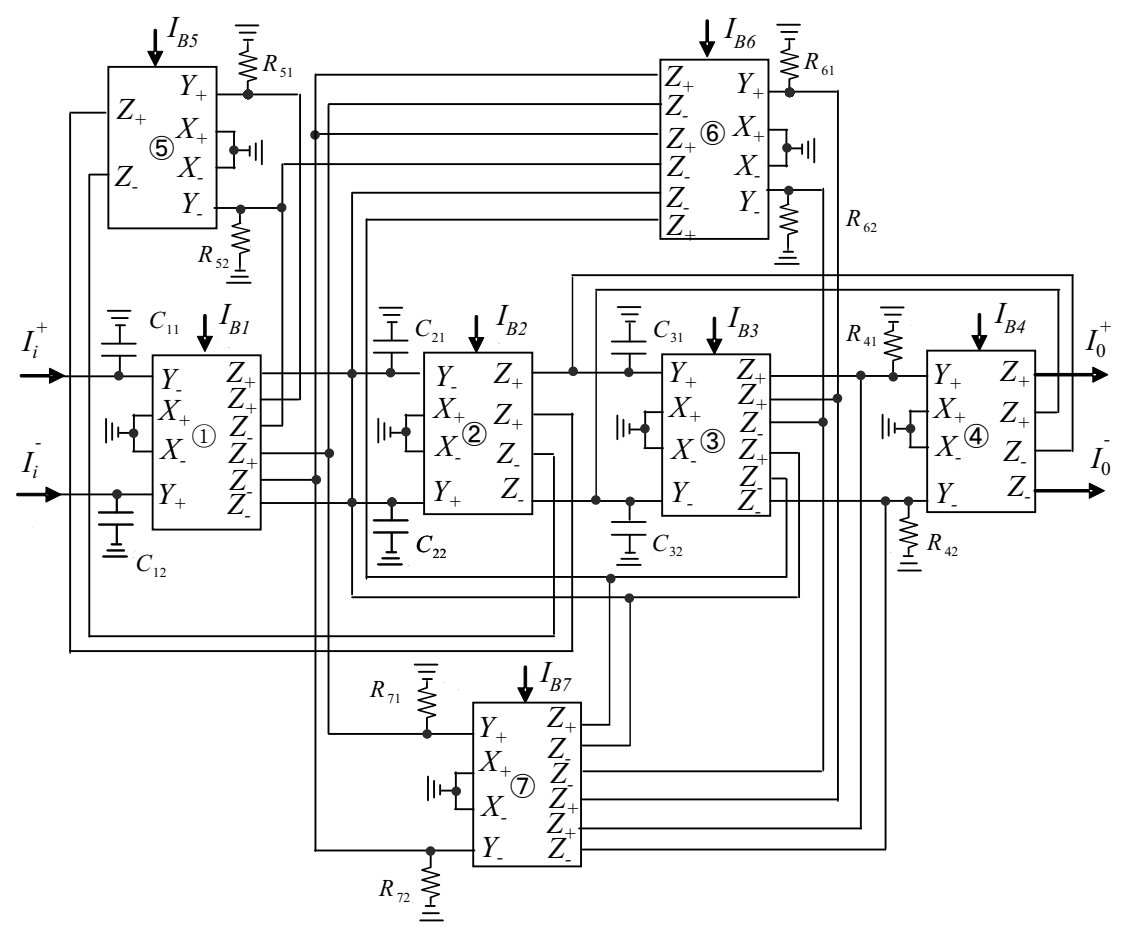

Fig. 12. The CFBCCII based $3^{\text {rd }}$-order elliptic low-pass ladder filter 


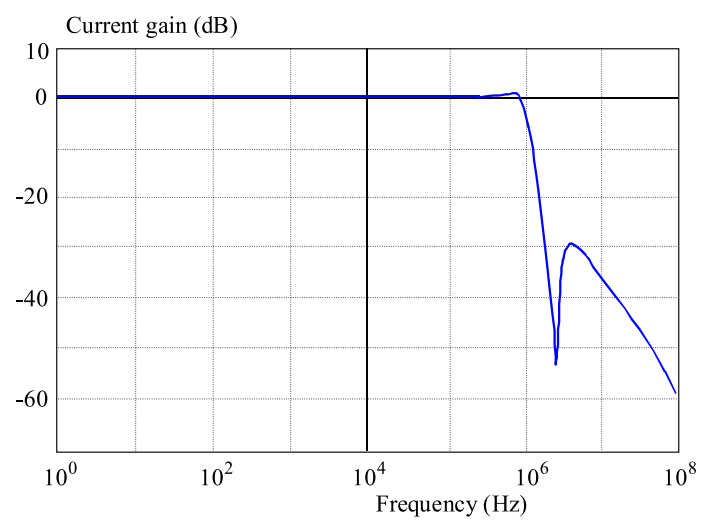

Fig. 13. The frequency response of the current gain

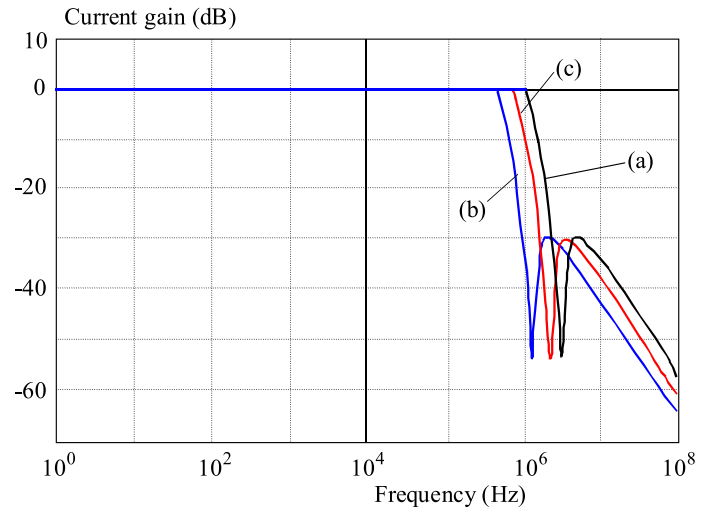

Fig. 14. Simulated frequency response of the current gain with different cut-off frequency

Table 2. Parameter setting for the proposed filter

\begin{tabular}{ccccc}
\hline CFBCCII & Transfer function & $R_{X}$ & $R$ & $C$ \\
\hline 1 & $1 /\left[s R_{0}\left(C_{1}+C_{2}\right)\right]$ & $R_{X 1}=R_{0}$ & - & $C_{11}=C_{12}=C_{1}+C_{2}$ \\
2 & $R_{0} / s L_{2}$ & $R_{X 2}=R_{0}$ & - & $C_{21}=C_{22}=L_{2} / R_{0}^{2}$ \\
3 & $1 /\left[s R_{0}\left(C_{2}+C_{3}\right)\right]$ & $R_{X 3}=R_{0}$ & - & $C_{31}=C_{32}=C_{2}+C_{3}$ \\
4 & $R_{0} / R_{L}$ & $R_{X 4}=R_{L}$ & $R_{41}=R_{42}=R_{0}$ & - \\
5 & $-R_{0} / R_{S}$ & $R_{X 5}=R_{S}$ & $R_{51}=R_{52}=R_{0}$ & - \\
6 & $C_{2} /\left(C_{1}+C_{2}\right)$ & $R_{X 6}=C_{1}+C_{2}$ & $R_{61}=R_{62}=C_{2}$ & - \\
7 & $-C_{2} /\left(C_{2}+C_{3}\right)$ & $R_{X 7}=C_{2}+C_{3}$ & $R_{71}=R_{72}=C_{2}$ & - \\
\hline
\end{tabular}

\subsection{Parameter Setting}

As shown in Fig. 12, the filter consists of 7 CFBCCIIs, and all of them are numbered. The $1^{\text {st }}$ CFBCCII is connected as a integrator, whose transfer function can be obtained as $1 /\left[s R_{0}\left(C_{1}+C_{2}\right)\right]$. According to (3), the intrinsic resistance in $\mathrm{X}$ terminal of the first CFBCCII can be written as $R_{X 1}=R_{0}$, and the values of the capacitors would be $C_{11}=C_{12}=C_{1}+C_{2}$. The $2^{\text {nd }}$ CFBCCII acts as a integrator whose transfer function is $R_{0} /\left(s L_{2}\right)$. Setting the value of $R_{X 2}$ to be $R_{X 2}=R_{0}$, then the capacitor values are: $C_{21}=C_{22}=L_{2} / R_{0}^{2}$. The $3^{\text {rd }} \mathrm{CF}$ BCCII, also acts as an integrator, whose transfer function is $1 /\left[s R_{0}\left(C_{2}+C_{3}\right)\right]$, so $C_{31}=C_{32}=C_{2}+C_{3}$, and $R_{X 3}=R_{0}$. The $4^{\text {th }}$ to $7^{\text {th }}$ CFBCCIIs act as scaling elements, and their gains are $R_{0} / R_{L},-R_{0} / R_{S}$, $C_{2} /\left(C_{1}+C_{2}\right)$ and $C_{2} /\left(C_{2}+C_{3}\right)$, respectively. Then one can obtain: $R_{41}=R_{42}=R_{0}, R_{X 4}=R_{L}, R_{51}=R_{52}=$ $R_{0}, R_{X 5}=R_{S}, R_{61}=R_{62}=C_{2}, R_{X 6}=C_{1}+C_{2}$, $R_{71}=R_{72}=C_{2}, R_{X 7}=C_{2}+C_{3}$. All the parameters are shown in Table 2 .

\section{DESIGN EXAMPLE}

A third order elliptic filter can be designed according to the analysis above. The $-3 \mathrm{~dB}$ cut-off frequency is selected to be $f_{c}=1 \mathrm{MHz}$, the matching impedance is $R_{r}=1 \mathrm{~K} \Omega$. Considering an elliptic filter with a passband ripple of $0.0109 \mathrm{~dB}$, and a stopband ripple of $28 \mathrm{~dB}$, and consulting the elliptic function normalized parameter $\mathrm{C}$ 0305-20 yields the normalized filter parameters as follows
[27]: $C_{1}^{\prime}=C_{3}^{\prime}=0.5728, C_{2}^{\prime}=0.1043, L^{\prime}=0.8545$, $R_{S}^{\prime}=R_{L}^{\prime}=1$. According to the normalized equations, $C=C^{\prime} /\left(2 \pi f_{c} R_{r}\right)$ and $L=L^{\prime} R_{r} /\left(2 \pi f_{c}\right)$, the parameters in Fig. 10 can be obtained as $C_{1}=C_{3}=$ $C_{1}^{\prime} /\left(2 \pi f_{c} R_{r}\right)=91.2 \mathrm{pF}, C_{2}=C_{2}^{\prime} /\left(2 \pi f_{c} R_{r}\right)=16.6 \mathrm{pF}$, $L_{2}=L^{\prime} R_{r} /\left(2 \pi f_{c}\right)=1.36 \times 10^{-4} \mathrm{H}, R_{S}=R_{L}=$ $R_{S}^{\prime} R_{r}=R_{L}^{\prime} R_{r}=1 \mathrm{~K} \Omega$, and the virtual resistor $R_{0}$ is set to be $R_{0}=1 \mathrm{~K} \Omega$.

According to Table 2, the parameters in Fig. 12 can be calculated: $C_{11}=C_{12}=C_{1}+C_{2}=107.8 \mathrm{pF}, C_{21}=$ $C_{22}=L_{2} / R_{0}^{2}=136 \mathrm{pF}, C_{31}=C_{32}=C_{2}+C_{3}=$ $107.8 \mathrm{pF}, R_{X 1}=R_{X 2}=R_{X 3}=1 \mathrm{~K} \Omega, R_{X 4}=R_{X 5}=$ $1 \mathrm{~K} \Omega, R_{X 6}=C_{1}+C_{2}=107.8 \times 10^{-12} \Omega, R_{X 7}=C_{2}+$ $C_{3}=107.8 \times 10^{-12} \Omega, R_{41}=R_{42}=R_{51}=R_{52}=R_{0}=$ $1 \mathrm{~K} \Omega, R_{61}=R_{62}=R_{71}=R_{72}=C_{2}=16.6 \times 10^{-12} \Omega$. Notice that the value of resistors $R_{61}, R_{62}, R_{71}, R_{72}$, $R_{X 6}$, and $R_{X 7}$ are very small in practice, as the $6^{\text {th }}$ and $7^{\text {th }}$ CFBCCIIs act as scalers. If one multiplies the transfer functions with the same factor, the transfer functions would not change, so they can be rewritten as follows: $H(s)_{6}=\left[C_{2} \times 10^{13}\right] /\left[\left(C_{1}+C_{2}\right) \times 10^{13}\right], H(s)_{7}=\left[C_{2} \times\right.$ $\left.10^{13}\right] /\left[\left(C_{2}+C_{3}\right) \times 10^{13}\right]$, then $R_{X 6}=\left(C_{1}+C_{2}\right) \times 10^{13}=$ $1.078 \mathrm{~K} \Omega, R_{X 7}=\left(C_{2}+C_{3}\right) \times 10^{13}=1.078 \mathrm{~K} \Omega, R_{61}=$ $R_{62}=R_{71}=R_{72}=C_{2} \times 10^{13}=166 \Omega$. One can see that the 7 intrinsic resistances $R_{X}$ are $1 \mathrm{~K} \Omega$. According to (2), the bias current of each CFBCCII can be obtained as $I_{B 1}=I_{B 2}=I_{B 3}=I_{B 4}=I_{B 5}=I_{B 6}=I_{B 7}=60 \mu \mathrm{A}$. Simulation on the power dissipation has also been made, and it is found to be $22 \mathrm{~mW}$. 


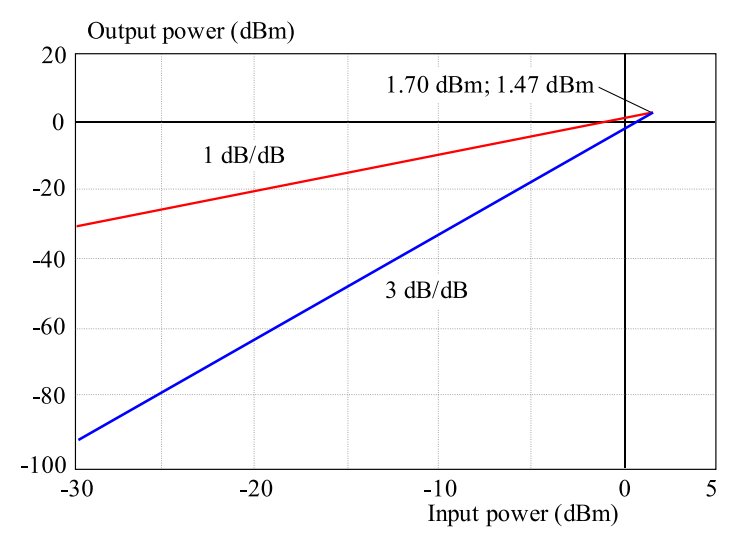

Fig. 15. Simulated frequency response of the current gain with different cut-off frequency

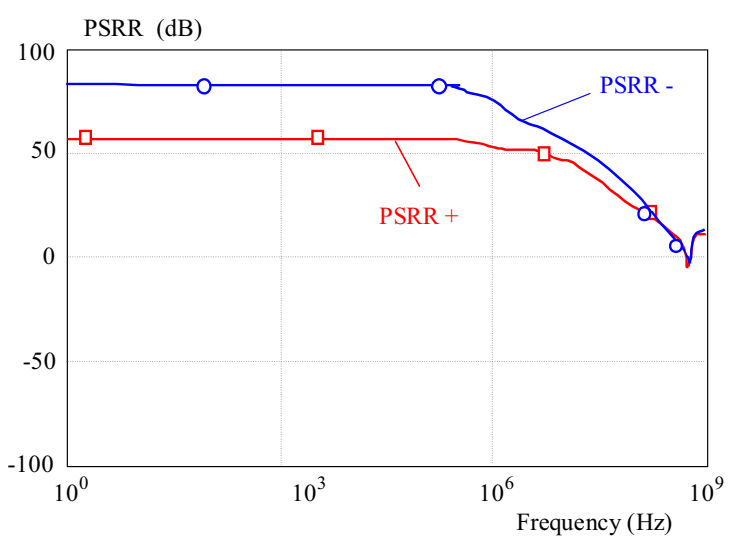

Fig. 16. The power supply rejection ratio of the CFBCCII based $3^{\text {rd }}$-order elliptic filter

This filter is simulated in Cadence Spectre Using Chartered $0.35 \mu \mathrm{m}$ CMOS process parameters. The configuration of the building block CFBCCII is shown in Fig. 3, and the dimensions of CMOS transistors are listed in Table 1. Supply voltages of the filter are $\pm 1.65 \mathrm{~V}$, and bias current of each CFBCCII is $60 \mu \mathrm{A}$, the parameters of the passive elements are set as: $C_{11}=C_{12}=$ $C_{31}=C_{32}=107.8 \mathrm{pF}, C_{21}=C_{22}=136 \mathrm{pF}, R_{41}=$ $R_{42}=R_{51}=R_{52}=1 \mathrm{~K} \Omega, R_{61}=R_{62}=R_{71}=R_{72}=$ $166 \Omega$. The frequency response of the transfer function is shown in Fig. 13. The passive filter has a passband ripple of $0.0109 \mathrm{~dB}$ and a stopband ripple of $28 \mathrm{~dB}$. The figure shows the elliptic filter has a cut-off frequency of $1.06 \mathrm{MHz}$, which is $600 \mathrm{~Hz}$ larger than the designed frequency, a passband ripple of $0.012 \mathrm{~dB}$, which is $0.001 \mathrm{~dB}$ larger than the standard value, and a stopband ripple of $29.2 \mathrm{~dB}$, which is in accordance with the standard value.

When we change the bias currents of the $6^{\text {th }}$ CFBCCII, the intrinsic resistance $R_{x 6}$ will be varied. Referring to Table 2 and the aforementioned analysis, the equation can be obtained as: $R_{X 6}=\left(C_{1}+C_{2}\right) \times 10^{13}$. According to the normalized equation $C_{1}+C_{2}=\left(C_{1}^{\prime}+\right.$ $\left.C_{2}^{\prime}\right) /\left(2 \pi f_{c} R_{r}\right)$ and $(2)$, the relationship between the bias current and the cut-off frequency can be obtained as $f_{c}=\left[\left(C_{1}^{\prime}+C_{2}^{\prime}\right) \sqrt{2 K_{\text {eff }} I_{B}} / \pi R_{r}\right] \times 10^{3}$; It is obvious that the cut-off frequency can be adjusted by bias current tuning. Simulations are made to demonstrate the tuning characteristic of this circuit. Figure 14 shows the frequency response of the current gain with different $3 \mathrm{~dB}$ frequencies. There are three curves in the figure, curve (a) shows the situation when the bias currents are equal to $60 \mu \mathrm{A}$ and $f_{c}=1 \mathrm{MHz}$, Curve (b) shows the second situation: when the bias current of the $6^{\text {th }}$ CFBCCII is set to be $40 \mu \mathrm{A}$, then $C_{11}=C_{12}=C_{1}+C_{2}=122 \mathrm{pF}$, so the cut-off frequency should be $883 \mathrm{KHz}$. Curve (c) shows the situation when the bias current of the $6^{\text {th }}$ CFBCCII $I_{B 6}$ is set to be $50 \mu \mathrm{A}$, where $C_{11}=C_{12}=C_{1}+C_{2}=112 \mathrm{pF}$, and the cut-off frequency is $963 \mathrm{KHz}$.

Figure 15 shows the linearity of this circuit, and one can see that the input third-order intercept point (IIP3) is $1.7 \mathrm{dBm}$, indicating that the circuit has good linearity property. Figure 16 shows the simulation results of the power supply rejection ratio (PSRR) of the filter, PSRR from the positive supply to the output $\left(\mathrm{PSRR}_{+}\right)$is $57 \mathrm{~dB}$, and PSRR from the negative supply to the output (PSRR - ) is $83 \mathrm{~dB}$. It can be seen that PSRR of the filter is high, this is partly because of the fully balanced structure, and then the noise at the output contributed by the ripple on the power supplies can be partly counteracted.

\section{CONCLUSIONS}

This paper proposes a new element, so called a current controlled fully balanced second-generation current conveyor circuit (CFBCCII) which employs a fully balanced structure to suppress common-mode signals. Then, a current-mode elliptic filter synthesis procedure using CFBCCII is proposed. Although the filter realization is complicated, it has following advantages: (1) The fully balanced circuit structure of the filter can suppress even harmonics and common-mode signals, effectively. (2) The cut-off frequency of the filter can be controlled by adjusting the bias current of CFBCCII. (3) The SFG approach is intuitive and simple. (4) The filter maintains the lowsensitivity properties of its LC prototype. (5) All passive filter components are grounded.

\section{Acknowledgement}

The authors would like to thank Ali Ümit Keskin in Yeditepe University, Turkey for the English improvements of this paper. This work was supported by National Natural Science Foundation of China under No 60676021, the Open Fund Project of Key Laboratory in Hunan Universities No 10K016 and the Research Innovation Project for Graduate in Hunan province No 521298376.

\section{REFERENCES}

[1] PAPAZOGLOU, C. A.-KARYBAKAS, C. A. : Noninteracting Electronically Tunable CCII-Based Current-Mode Biquadratic Filters, IEE Proc. Circ. Device Syst 144(3) (1997), 178-184.

[2] SUN, Y.-HE, Y.: Active Filters Using Single Current Conveyor, In Proc. of the 2003 IEEE Int. Conf. Robotics, Intelligent Systems and Signal Processing, 2003,, pp. 1130-1134. 
[3] KOKSAL, M.-SAGBAS, M.: A versatile signal flow graph realization of a general current transfer function. Int. J. Electron. and Commun. 62(1), 33-40(2008).

[4] CHUn-Ming, C.-SOliman, A. M.-SWAMY, M. N. S.: Analytical Synthesis of Low-Sensitivity High-Order VoltageMode DDCC and FDCCII-Grounded R and C All-Pass Filter Structures, IEEE trans. Circ. syst.-I: regular papers 54(7) (2007), 1430-1443.

[5] JIRASEREE-AMORNKUN, A.-TANGSRIRAT, W.-SURAKAMPONTORN, W. : Tunable Elliptic Filters Using Multioutput Current Controlled Conveyors, In Proc. of IEEE Region 10 Conference on TENCON, 2004, pp. 229-232.

[6] WU, J.-Ei-MAASRY, E. : Current-Mode Ladder Filters Using Multiple Output Current Conveyors, IEEE Proc. Circ. Devices Syst. 143(4) (1996), 218-222.

[7] KESKIN, A. Ü.-CAM, U. : Insensitive High-Output Impedance Minimum Configuration SITO-Type Current-Mode Biquad Using Dual-Output Current Conveyors and Grounded Passive Components, AEU- Int. J. Electron. Commun. 61(5) (2007), 341-344.

[8] SHI, W. X.-HAN, Q. Q.-WANG, C. Y.: Fully Differential Current-Mode Filter Based on MDDCC, In Proc. of IEEE Asia-Pacific Conference on Circuits and Systems, 2000, pp. $674-677$.

[9] CHIU, W.- LIU, S. I.-CHEN, J. J. : CMOS Differential Difference Current Conveyors and their Application, IEE ProceedingsG: Circuits Devices and Systems 143(2) (1996), 91-96.

[10] ElWAN, H. O.-SOLIMAN, A. M.: Novel CMOS Differential Voltage Current Conveyor, IEE Proceedings-G: Circ. Devic. Syst. 144 (3) (1997), 195-200.

[11] KUMAR, V.-KESKIN, A. U.-PAL, K. : DVCC-Based Single Element Controlled Oscillators Using All-Grounded Components and Simultaneous Current-Voltage Mode Outputs, Frequenz. 61(3) (2007), 141-144.

[12] El-ADAWY, A.-SOlimAN, A. M.-ELWAN, H. O. : A Novel Fully Differential Current Conveyor and Applications for Analog VLSI, IEEE trans. Circ. Syst.-II: Analog and Digital Processing 47(4) (2000), 306-313.

[13] MAHMOUD, A. S.: Fully Differential CMOS CCII Based on Differential Difference Transconductor, Analog Integrated Circuit and Signal Processing 50(3) (2007), 195-203.

[14] ALZAHER, H. A.-ELWAN, H.-ISMAIL, M. : A CMOS Fully Balanced Second-Generation Current Conveyor, IEEE Trans. Circ. Sys.-II. 50(6) (2003), 278-287.

[15] ALZAHER, H. A.: CMOS Highly Linear Fully Differential Current Conveyor, Electron. Lett. 40(4) (2004), 214-216.

[16] HASSANEINA, W. S.-AWADB, I. A.-SOLIMAN, A. M.: : New high accuracy CMOS current conveyors, Int. J. Electron. Commun. (AEÜ) 59 No. 7 (2005), 384-391.

[17] MORADZADEH, H.-AZHARI, S. J. : Low-voltage low-power rail-to-rail low-Rx wideband second generation current conveyor and a single resistance-controlled oscillator based on it, IET Circuits, Devices \& Systems 5 No. 1 yr2011, 66-72.

[18] JERABEK, J.-VRBA, K. : SIMO type low-input and high-output impedance current-mode universal filter employing three universal current conveyors, Int. J. Electron. Commun. (AEÜ) vol64 No. 6, (2010), 588-593.

[19] FABRE, A.-SAAID, O.-BOUCHERRON, C.: High Frequency Applications Based on a New Current Controlled Conveyor, IEEE Trans. Circ. Sys.-I: Fundamental Theory and Applications 43 No. 2 (1996), 82-91.

[20] WANG, C. H.-LI, J.: A CMOS Differential Current-Controlled Second Generation Current Conveyor, In Proc. of 6th Int. Conf. ASIC, Shanghai, China, 2005, pp. 447-450.

[21] ZOUAOUI, H.-FABRE, A.: A New Balanced CMOS Controlled Integrator for Ultra High Frequency Applications, Analog Integrated Circuits and Signal Processing 47 (2006), 13-22.
22] SCHMid, H.-MOSCHYTZ, G.: Tunable CCII-MOSFET-C Filter Biquads for Video Frequencies, In Proc. of ECCTD, Budapest, 1997, pp. 82-87.

23] WYSZYNSKI, A.-SCHAUMANN, R.-SZCZEPANSKI, S.HALEN, P. V.: Design of a $2.7 \mathrm{GHz}$ Linear OTA and a 250 $\mathrm{MHz}$ Elliptic Filter in Bipolar Transistor-Array Technology, IEEE Trans. on Circ. Syst. Part II. 40(1) (1993), 19-31.

[24] KOZIEL, S.-SZCZEPANSKI, S.: Design of Highly Linear Tunable CMOS OTA for Continuous-Time Filters, IEEE trans. circ. syst.-II: Analog and Digital Signal Processing 49(2) (2002), 110-122.

[25] ZHU, X.-SUN, Y. C.-MORITZ, J. : Design of Current-Mode gm-c mlf Elliptic Filters for Wireless Receivers, In Proc. of 15th IEEE Int. Conf. Electron. Circ. Systems, 2008, pp. 296-299.

[26] JIRASEREE-AMORNKUN, A.-TANGSRIRAT, W.-SURAKAMPONTORN, W.: Tunable Elliptic Filters Using MultiOutput Current Controlled Conveyors, IEEE Trans. Circ. Syst. 4 (2004), 229-232.

27] JIRASEREE-AMORNKUN, A.-SURAKAMPONTORN, W. : Efficient Implementation of Tunable Ladder Filters Using MultiOutput Current Controlled Conveyors, Int. J. Electron. Commun. (AEU) 26(1) (2008), 11-23.

28] OZOGUZ, S.-TOKER, A.: Tunable Ladder-Type Realization of Current-Mode Elliptic Filters, Int. J. Electron. Commun 56(3) (2002), 193-199.

29] WANG, C. H.-SHE, Z. X.-LIU, H. G. : New CMOS Current-Controlled Second Generation Current Conveyors, In Proc. of 4th IEEE Int. Conf. Circ. Syst. Communicationyr 2008, pp. 333-337.

Received 8 January 2010

Qiujing Zhang was born in Jishou, Hunan, China, in 1982. She received the BSc from School of Computer and Communication, Changsha University of science and technology, in 2005. She is now studying in Key Laboratory of Advanced Communication Technology in Hunan Universities, College of Information Science and Technology, Hunan University for $\mathrm{PhD}$ degree. She is interested in analog IC circuit and filter design.

Chunhua Wang was born in Yongzhou, China, in 1963. He received the BSc degree from Hengyang Teachers College, Hengyang, China, in 1983, the MSc degree from Physics Department, Zheng Zhou University, Zheng Zhou, China, in 1994, the PhD degree from School of Electronic Information and Control Engineering, Beijing University of Technology, Beijing, China. He is currently a Professor of Key Laboratory of Advanced Communication Technology in Hunan Universities, College of Information Science and Technology, Hunan University, Changsha, China. From 2004 to 2005, he served as a Professor and the associate Dean of Information Engineering, Xiangtan University, Xiangtan, China. His research interests include current-mode circuit design, filtering, radio frequency circuit and wireless communications.

Jingru Sun was born in Liaoyuan, China, in 1977, she received the BSc degree from Changchun University, Changchun, china, in 2000, the MSc degree from Northeastern University, Shen Yang, China, in 2004. She is currently a teacher and a doctoral student of Key Laboratory of Advanced Communication Technology in Hunan Universities, College of Information Science and Technology, Hunan University, Changsha, China. Her research interests include current-mode circuit design, filtering and radio frequency circuit.

Sichun Du received the ME degree in Computer Application Technology from Hunan University, Changsha, China. His current research interests include design and simulation of RF CMOS integrated circuits and mixed analog-digital circuits. 